\title{
A UNIVERSIDADE E SUA RESPONSABILIDADE SOCIAL'
}

\author{
Marina Tazón Volpi ${ }^{2}$
}

SINTTESE - 0 artigo apresenta enfoques de diferentes autores sobre a responsabilidade social da Universidade. Enfatiza sua importância na formação integral do individuo para a sociedade do futuro, devendo constituir-se num espaço social que privilegie a criação e a instigação da criatividade, preparando, assim, o homem para a vida num mundo em constante transformação mediante a ativação de sua capacidade reflexiva, buscando configurar novas respostas às necessidades da sociedade. A Universidade como a instituição que, aberta para o diálogo com seu entorno, deverá buscar soluções concretas para os problemas do presente e do futuro, mediante a formação de profissionais de acordo com a real demanda social, da investigação direcionada para a interdisciplinaridade e a integração do científico com o humanístico, numa efetiva vivência da solidariedade social.
ABSTRACT - The article presents the focus of different authors on the social responsibility of the University. It highlights its importance in the integral formation of the individual as regarding the society of the future, that necessarily consists of a social space that gives due privilege to creation and instigates creativity, thus preparing man for an ever changing world by activating his reflexive capacity, while it seeks the making up of new answers to the needs of society. The university, as an institution that is open to interact with the world that surrounds it, shall search for sound solutions for present and future problems by forming professionals in accordance with actual social requirements, of investigations leading to a close relationship among subjects and the integration of science and humanism in an effective experience of social solidarity.

\begin{abstract}
"Se queremos que a vida futura seja uma vida plenamente humana, é indubitável que a Universidade não pode deixar de contribuir para os esforços tendentes à organização sistemática das premissas necessárias nesse sentido. Pois a Universidade [...] é um centro de ação criadora em relação com a vida e a cultura. Nela têm lugar discussões acerca dos valores fundamentais do humanismo e sobre seus métodos de compreensão e de continuação: é na Universidade onde a ciência se submete ao fogo da crítica e a criatividade, com o que pode distribuir uma cultura viva e refletida". Suchodolski (1979, p. 429-430)
\end{abstract}

1 O presente artigo constitui o segundo capitulo da tese de doutorado Testemunhos de professores sobre sua ação profissional e a responsabilidade social da universidade: docentes da PUCRS pensam sua universidade, apresentada na PUCRS em 26 de maio de 1995.

Coordenadora do Departamento de Letras Estrangeiras do Instituto de Letras e Artes da PUCRS.

\begin{tabular}{|l|l|l|l|l|l|}
\hline VERITAS & Porto Alegre & v. 41 & $n^{2} 161$ & Março 1996 & p. 117-133 \\
\hline
\end{tabular}


Ao longo de sua história, o ensino superior tem passado por profundas e substanciais modificações, mas talvez nunca sua responsabilidade social tenha estado tão evidenciada como nos dias de hoje.

Num mundo em constante e acelerado processo de renovação, as estruturas e funções tradicionais da Universidade se deparam com uma série de desafios. Sendo assim, suas tarefas devem se incrementar e transformar para poder enfrentá-los, na busca de respostas concretas e eficazes para as novas necessidades da sociedade de hoje e, principalmente, a do futuro.

Muito se tem escrito e debatido sobre a função da Universidade e, em geral, nessas circunstâncias, a ênfase tem-se centrado em seu papel de produtora e transmissora de conhecimento. Mas como vem ela cumprindo seu papel? Que tipo de conhecimento vem produzindo, e, principalmente, como o tem socializado? $\mathrm{Ou}$ será ela uma mera (re)produtora de conteúdos eruditos para um reduzido número de privilegiados zeladores do saber? E esse saber, de que se nutre? Que compromisso tem ela com as reais necessidades da nossa sociedade? Estará a Universidade com os pés firmados no real ou flutuará no distanciamento?

Azevedo (1991, p. 12), ao considerar a Universidade "uma instituição intimamente vinculada à conservação de uma cultura para poucos que efetivamente sempre mais se distancia e os distancia deste humus concreto no qual a sociedade como um todo e a própria Universidade em nossas latitudes", aponta para as conseqüências desse distanciamento, enfatizando o fato de a Universidade encontrarse fechada sobre ela mesma, o que redunda numa crescente diminuição de seu impacto sobre a sociedade.

Por outro lado, afirma o mesmo autor que a sociedade é pensada a partir dos enfoques, necessidades e possibilidades internas da Universidade e não, como seria desejável, a partir das reais necessidades e exigências da realidade. Como decorrência do anteriormente postulado, coloca a potenciação do elitismo, caracterizado pela consolidação dos métodos e processos de criar e transmitir o conhecimento, encarado como propriedade por um restrito número de iniciados, acarretando, assim, a ruptura da comunicação acadêmica inter e transdisciplinar e impedindo o diálogo direto e enriquecedor com a sociedade.

É a partir dessas circunstâncias que Azevedo (1991, p. 12) aponta para uma universidade que busque a incorporação da realidade e do universo cultural e social como fonte de conhecimento e matriz do saber. Uma universidade que coloque o conhecimento assim produzido a serviço efetivo da sociedade, promovendo, dessa forma, um questionamento basilar para a transformação do status quo e o surgimento de "uma sociedade melhor, isto é, mais livie e responsável, mais justa e participativa".

Essa perspectiva é compartilhada por Mosquera (1990, p. 7), ao afirmar que além de seu papel cultural e educativo mediante a socialização do saber, a Universidade deve cumprir com duas outras funções precípuas: de crítica e participação, "tomando como base o conhecimento da realidade social e produzindo conhecimentos que possam influir sobre os modelos sociais, econômicos, políticos e culturais [...]" o que "implica valores alternativos que configuram uma instituição claramente participativa e cujos indicativos são a pluralidade dos enfoques, desejando e fazendo o pensar e o agir". 
Não podemos ignorar o fato de que a produção de conhecimentos é uma das tarefas fulcrais da Universidade. Entretanto, cabe fazer, aqui, algumas considerações a respeito da destinação social desse conhecimento. Para quem e para que se produz o saber? Nesse particular, acreditamos que a contribuição da Universidade não deve limitar-se somente a prover a sociedade de recursos humanos adequadamente qualificados para o desenvolvimento sócio-econômico.

$\mathrm{O}$ acadêmico, ao adquirir conhecimentos necessários para exercer uma atividade específica numa sociedade que requer seus serviços e sua participação, deve ser capaz de responder às expectativas nele depositadas mediante a concretização de um compromisso não só com ele mesmo mas com seus semelhantes, com a vida e com a sociedade como um todo. E é na Universidade onde esses fundamentos de estreita relação entre o profissionalismo e o respeito ao ser humano e aos seus direitos deve solidificar-se, na busca da construção de uma sociedade mais justa.

Assim, a Universidade deverá também produzir o saber buscando o equilíbrio entre o conteúdo social e a excelência acadêmica especificamente profissional, num explícito comprometimento com a elevação das condições de vida a níveis mais dignos e fraternos, numa significativa interação com o entorno social onde se situa, cumprindo, assim, o papel que cada vez mais é chamada a desempenhar.

Dessa maneira, para melhor cumprir sua função social, é imprescindível que a Universidade não se descuide da formação integral dos acadêmicos, uma formação que, como destaca Mosquera (1990), vá mais além da competência técnica, resgatando o compromisso com o humano, na busca da sintese do profissional com o ser humano que há nele, numa perspectiva de educação de valores, capaz de propiciar-lhe um posicionamento ético para assumir seu papel numa sociedade em constante mudança. Nessa linha de posicionamento, o referido autor $(1992$, p. 53) destaca "a relevância da educação moral de um mundo que precisa ser melhor equacionado e conhecido onde não apenas impere o 'saber tecnológico' ou o 'saber científico', mas onde exista um respeito fundamental pela pessoa humana no seu encontro com os outros à procura de valores mais válidos e coerentes".

Parece-nos oportuno, ainda dentro do enfoque da educação de valores, destacar o posicionamento de Zilles (1992, p. 36), ao abordar a questão da suposta objetividade no mundo de hoje. Ao afirmar que muitas vezes a ciência coloca entre parênteses 0 objeto global mediante a racionalização e a objetividade cientifica, aponta essa dimensão como responsável pela formação de profissionais que, por mais que desvelem o conhecimento científico, não estão preparados para cumprir sua função social, já que "o mundo da pura objetividade e da pura racionalidade torna-se [...] um mundo inabitado e inabitável".

Assim, a necessidade de uma educação voltada para o aperfeiçoamento da prática social, segundo esse autor (1992, p. 33), constrói a figura do valor na ação, pois, em sua opinião, "o valor é a conjugação da liberdade com a exigência, com o desejo da vontade que quer o bem, buscando sua realização. A razão descobre os fins do ser e, através da liberdade, encarna-os na existência, plasmando o dever ser no interior do ser". 
A partir do que foi anteriormente exposto, julgamos oportuno, neste momento, apresentar, mais a fundo, o pensamento de alguns autores que, sob diversos enfoques, tratam as funções da Universidade e sua atuação nos dias de hoje.

Berchen (1992, p. 38), ao abordar o tema da função cultural da Universidade, enfatiza seu caráter eminentemente cientifico, não esquecendo, por outro lado, a íntima relação entre cultura e ciência ao afirmar: "Se eu entendo por cultura esse processo global de desabrochar das faculdades humanas na confrontação com a natureza, com a vida social, na criação de uma esfera de atividade intelectual fora do trabalho e da vida prática, então essa definição do termo cultura, a ciência está incluída".

Nesse mesmo trabalho (p. 41) aponta quatro dimensões que, para ele, caracterizam a função da Universidade: a preservação do saber humano, a transmissão do saber à jovem geração, o aumento e o enriquecimento do saber graças à pesquisa e a assimilação espiritual da ciência, concluindo que: "[...] assim como a conservação do saber está ligada à sua transmissão e a pesquisa é inseparável do ensino, da mesma forma a Universidade não pode assumir realmente sua função cultural senão em conexão com suas outras tarefas sociais".

Esse autor, ao encarar a Universidade como o lugar por excelência da preservação do conhecimento, afirma que tanto nas cabeças pensantes dos intelectuais que dela fazem parte como no ambiente físico de suas bibliotecas está depositado grande parte do cabedal do saber da Humanidade. Ao mesmo tempo, afirma ser esta uma função marcadamente cultural, pelo fato de a Universidade não limitar-se à manutenção do saber, mas compartilhá-lo com seu entorno local, nacional e internacional.

A função da transmissão do saber é encarada como um processo mais complexo do que a mera transferência de conhecimentos técnico-científicos aos acadêmicos, como uma frutifera interação entre estes e seus professores, através de questionamentos e debates. A interação, assim vista, se constitui em fator desencadeador de mútuo desenvolvimento e um incentivo à pesquisa e à otimização da qualidade também do docente, num processo dialógico que mantém vivo o elo entre a conservação e a transmissão do conhecimento e seu constante avanço mediante a investigação, com conseqüente aperfeiçoamento do processo de ensino e de aprendizagem.

Neste aspecto, Berchen (1992) coincide com a posição de Suchodolski (1979) que, da mesma forma, opina ser a Universidade o espaço onde o saber deve sujeitar-se à crítica e à criatividade, para poder produzir e socializar uma cultura vivida e solidamente fundamentada.

Ao tratar dessas duas funções apontadas por Berchen (1992), seria interessante questionar se na sociedade hodierna, onde os meios de comunicação evoluíram de forma gigantesca, ocupando enormes espaços culturais e a informatização está extremamente generalizada, facilitando o armazenamento de um número praticamente infinito de informações, seria a Universidade o único e exclusivo lugar onde o saber pode ser realmente preservado e se seria ela a única capaz de transmitir e socializar o conhecimento. E, no caso de a resposta ser negativa, perguntar-nos o que deve essa instituição fazer e que rumos deve tomar para, nessas circunstâncias, cumpri-las adequadamente. 
É na atividade de investigação que Berchen (1993) centra a função de aumento e enriquecimento do saber. Através da pesquisa, segundo ele, a Universidade pode - e deve - acompanhar o rápido avanço da Ciência e as céleres alterações culturais, pois é ela que pode propiciar à Universidade a possibilidade de colocar no mercado de trabalho profissionais em condições de atuar com competência, em uma sociedade que não pára de evoluir tecnológica e cientificamente.

Cabe ressaltar aqui que Escotet (1992, p. 48) coloca clara e criticamente a dificuldade que as universidades têm em acompanhar esse rápido desenvolvimento ao afirmar que "a Universidade, em boa parte, tem sido incapaz de dar informação científica ao mesmo tempo em que esta se produz", já que, segundo ele, é fora dessa instituição que as pesquisas, e conseqüentemente o conhecimento cientifi$\mathrm{co}$, se incrementam de forma mais eficaz, sendo que "inclusive nos países industrializados existem até o momento poucas opções para que as instituições existentes possam adaptar-se às novas realidades que o ritmo da mudança gera".

A quarta função explicitada por Berchen (1992) é a assimilação e digestão intelectual do saber. Cabe, conforme o autor, aos professores a tarefa de possibilitar amplas e acuradas reflexões a respeito do conhecimento adquirido e ministrado, bem como das possiveis conseqüências dos processos científicos e técnicos, de suas variadas aplicações a problemas práticos, através de um comportamento interdisciplinar, numa constante crítica e autocrítica do seu fazer intelectual. Essa postura por párte dos docentes virá a propiciar aos acadêmicos não apenas uma aprendizagem mecânica e robotizada dos conteúdos, mas a ordenação lógica do conhecimento científico e a capacidade de desenvolver o necessário espírito crítico que deve acompanhar todo o seu processo de formação.

Intimamente ligada a esta tarefa, o autor (p. 42) expõe seu posicionamento no que diz respeito à formação global do homem, ao manifestar que "enquanto a ciência e os métodos científicos concorrem na formação do indivíduo, as universidades guardarão uma missão de formação que vai mais além da transmissão de conhecimentos e de iniciativas científicas".

Ao mesmo tempo, ao ressaltar a importância da Universidade na transmissão de valores, afirma que não cabe a ela ditar valores, mas proporcionar o exercício do livre-arbítrio, num diálogo acadêmico permanente para, dessa maneira, poder decidir sobre os critérios de ação.

Ao concluir (p. 47), assinala que a Universidade servirá de modo mais efetivo à sociedade na medida em que, com a Ciência e através dela, possa contribuir para o desenvolvimento da cultura numa "orientação incondicional para a verdade e para a razão".

Escotet (1990), ao abordar a dialética da missão universitária, apresenta algumas idéias que, apesar de partirem de uma óptica mais crítica, vêm ampliar e complementar as reflexões de Berchen (1992) sobre o tema.

A partir da análise do paradigma sócio-econômico no cenário mundial e das radicais transformações que têm caracterizado a sociedade nos últimos anos em todos os âmbitos, tanto no mundo capitalista como no socialista, esse autor ( $p$. 212) procura aprofundar a discussão sobre a missão da Universidade num mundo onde "a falta de fraternidade, de solidariedade [...] é uma prova de que ainda estamos em uma escola atrasada do desenvolvimento do homem, do desenvolvimento 
social e econômico", destacando que esse desenvolvimento deve ocorrer por via da liberdade, da democracia, da participação e da eqüidade.

$\mathrm{O}$ autor coloca enfaticamente que a missão da Universidade tem ficado reduzida à ação de treinamento profissional, apontada por ele como legítima, porém insuficiente, já que, paradoxalmente, em vez de aumentar a qualidade da educação em nivel superior, vem contribuindo para o seu declínio, pois geralmente a procura pelos cursos universitários se baseia na possibilidade de conseguir um trabalho mais bem remunerado, sem que a busca da titulação seja acompanhada pela busca do conhecimento como um bem específico, sendo a principal motivação a obtenção de um título acadêmico que facilite a elevação do prestígio social.

Entretanto, contrariando essa expectativa, um grande contingente de egressos de cursos superiores tem dificuldade de encontrar emprego em sua área específica - inclusive em países do Primeiro Mundo - proliferando, assim, o número de desempregados e especialistas que não atuam nas funções para as quais foram treinados nas universidades.

Cabe, nesse particular, fazer menção ao fato de os egressos das universidades muitas vezes tenderem a ficar cada vez mais especializados, a ponto de, em determinadas áreas, sobrarem doutores (isto é, profissionais com doutorado). Esses especialistas são, em alguns casos, enviados a paises do Terceiro e Quarto Mundos com bolsas de estudos, vindo a trabalhar por algum tempo em Fundações (paralelamente ao mercado de trabalho) ou em convênios universitários (geralmente em órgãos oficiais) como empréstimo de técnicos ou ainda em empresas subsidiárias de grandes empresas multinacionais, agravando, assim, a situação funcional e a falta de perspectiva para o mercado de trabalho dos profissionais formados pelas universidades dos países que assimilam os oriundos do Primeiro Mundo.

O desenvolvimento cientifico-tecnológico no setor produtivo propicia a evolução dos conteúdos e das práticas de cada profissão, transformando demanda do mercado de trabalho. Para atender a essa demanda, este estrutura seus próprios cursos de treinamento e aperfeiçoamento, competindo com a Universidade tanto em eficiência como em recursos, obliterando, assim, uma função que até há pouso tempo estava reservada à Academia.

Tendo em vista que há uma clara tendência, no mundo, para incorporar um modelo econômico de mercado e que as instituições de ensino existentes têm apresentado enorme dificuldade para acompanhar as rápidas modificações e as novas necessidades sócio-econômicas e a elas adaptar-se, Escotet (1990) aventa para o perigo de que a Universidade venha a fugir da sua missão transcendental, qual seja a de geradora de conhecimentos e de criação intelectual.

Para que a Universidade possa cumprir eficazmente essas funções, é preciso que deixe de constituir-se apenas em uma instituição informadora e se transforme em uma Universidade geradora, onde a reflexão teórica e a investigação, intimamente imbricadas com a contribuição ética e estética, se instalem de maneira integral tanto no corpo docente quanto em seu alunado.

Uma Universidade dessa natureza, entretanto, deve estar em sintonia com a realidade para, dessa forma, colaborar na solução de problemas em todos os setores da atividade humana, exercitando sua capacidade reflexiva e assim poder, críti- 
ca e criativamente, antecipar-se aos acontecimentos, tentando configurar propostas viáveis para a sociedade do futuro.

Ao deparar-se, então, com o enorme dilema entre a tradição e a mudança, Escotet (1990, p. 216) afirma que é precisamente no campo da educação que se tem produzido menos modificações: "Nossa tendência - constata - tem sido a de manter tradições que deveriam mudar e mudar tradições que deveriam permanecer", e qualquer transformação pode gerar uma crise se não estivermos preparados para ela. É exatamente aí que o autor (p. 218) coloca o que, em seu entendimento, constitui o cerne da ação universitária: a Universidade há de ser o espaço capaz de "formar homens para a mudança permanente e, inclusive, para a eventual crise produto dessa mudança".

Assim sendo, a própria instituição universitária há de ser geradora de conhecimentos e mudanças, caracterizando-se ainda por sua preocupação em não apenas reproduzir estruturas sociais e conhecimentos já existentes, mas, pelo contrário, modificá-los e melhorá-los, num constante processo de criação que não pode nem deve deter-se, para acompanhar as rápidas mutações no campo social, político e cultural. Mas, ao mesmo tempo, constituir-se em uma entidade criadora e instigadora de criatividade, onde a investigação, a reflexão e o.questionamento intelectual venham a proporcionar inovações significativas em seu entorno.

Entretanto, essa empreitada a ser cumprida pela Academia exige que ela mesma passe por um processo de ajustamento e evolução, tanto no tempo como no espaço. Para isso, assinala Escotet (1990, p. 219), "não só será necessário modificar as normas e as estruturas, senão que será um imprescindivel renovar e desenvolver os espiritos e as vontades dos participantes das comunidades universitárias, e em especial, do docente, como nexo próprio para façilitar a-mais ampla circulação de idéias, projetos, experiências e programas".

O mesmo teórico, em trabalho posterior (1992, p. 53) salienta que esse processo de evolução vai repercutir diretamente em todas as metas que a Universidade se propõe a alcançar e, de forma peculiar, no que diz respeito à formação, por ele considerada "o eixo fundamental da nova missão universitária".

A acelerada evolução do conhecimento que caracteriza a pluralidade da Ciência em nossos dias acarreta, sem dúvida, uma multiplicação de disciplinas jamais imaginadas pelo homem. Essa complexidade e multiplicidade do saber atual fazem com que, muitas vezes, a Academia transmita conteúdos que já não possuem vigência ou, nos casos em que se consegue acompanhar os avanços científicos, os transmite de forma fragmentada, parcial ou incompleta, numa clara defasagem entre o que ensina e o mundo real, não preparando os alunos para nele viver. Conseqüentemente, torna-se indispensável a permanente atualização, que permita ensinar não a Ciência de ontem ou de hoje, mas a que mais próxima esteja do limiar do futuro.

Essa não é uma tarefa simples e demanda da Universidade uma profunda reflexão sobre sua função formativa. É nessa vertente onde se encontra outro desafio a ser enfrentado, e a solução passa, segundo Escotet (1992, p. 62), pelo caminho da educação permanente. Nesse particular, aponta que a Universidade "tem que dirigir-se para ajudar a pessoa a pensar: a ensinar a aprender: inculcar amor profundo pela idéia de conhecer; mais que dar informação, a saber onde buscá-la e como 
selecioná-la e interpretá-la; a gerar novos conhecimentos; a promover a educação afetiva e psicomotora, a criar consciência de comunidade, de participação, de respeito, de tolerância, de flexibilidade".

Calera (1990) aponta para a função social-transcendental da Universidade, chamando a atenção clara e incisivamente para a necessidade de superar a visão enviesada da instituição como uma simples distribuidora de títulos profissionais, já que, apesar de todas as dificuldades e problemas por que passa, continua sendo um espaço valioso para a realização de um trabalho enriquecedor e socialmente rentável. É essencial que "a Universidade seja algo mais do que uma escola de capacitação profissional e se constitua, também, em um lugar onde a cultura superior esteja realmente a serviço da libertação dos homens, isto é, de que todos os homens sejam donos de seu próprio destinado individual e coletivo".

Sua reflexão tem como ponto de partida a revolução cientifico-tecnológica por que a sociedade está passando e as radicais transformações que essa revolução acarretará para a Universidade no próximo século, ao propor novos problemas que exigirão respostas imediatas. Talvez o mais capital deles seja o de restituir ao homem o sentido da vida, num mundo onde, seguramente, surgirão novas formas de viver, sendo a informação e a tecnologia detentoras de um poder verdadeiramente avassalador.

Frente a essa realidade, a Universidade desempenhará um papel peremptório, no sentido de abrir a Ciência e a Tecnologia à sociedade, para evitar que essas forças venham a transformar-se em propriedade exclusiva de uma elite de peritos que, como depositários do conhecimento, possam impor novas e sofisticadas formas de totalitarismo.

A sua grande colaboração constará, então, segundo o autor (p. 20), em oportunizar uma reflexão crítica sobre os objetivos e o alcance dos novos avanços científicos e técnicos, tendo como missão "pensar a ciência e a técnica, isto é, discutir os fins a que servem ou podem servir esses meios cada vez mais sofisticados: avaliar publicamente as decisões dos poderes públicos sobre matérias científicas e técnicas, informar a sociedade de seus trabalhos e projetos e colocar-se em sintonia com a sociedade para a determinação dos objetivos sociais da ciência e da técnica".

$O$ autor assinala, também, algumas atitudes e tarefas que poderiam - e deveriam - adotar-se para que a Universidade cumprisse plenamente com sua função social transcendental, apesar das inúmeras dificuldades, condicionamentos e problemas com que se depara o trabalho universitário.

Em primeiro lugar, destaca a participação efetiva, em todos os âmbitos, a partir da consciência da importância e do valor da cultura, do ensino e da pesquisa, empregando todos os canais de participação que a Universidade possui, para não somente fazer as críticas que se julgarem necessárias mas para lutar por uma Universidade melhor.

O trabalho rigoroso é posto em relevo, especificando a necessidade, no âmbito do professorado, da existência de um ideal ético de trabalho, reforçado pelo estabelecimento de níveis de exigência com a qualidade, tanto no que se refere ao ensino quanto à pesquisa, num efetivo comprometimento com a sua tarefa, o que seguramente deverá redundar na otimização do funcionamento da Universidade. 
Um contínuo esforço dos docentes para manter-se atualizados e em sintonia com os temas e problemáticas mais relevantes da sociedade do nosso tempo é também apontado como fundamental para conduzir o ensino e a investigação, no sentido de aprofundar as questões de cuja solução possam depender um presente e um futuro mais promissores para a sociedade como um todo e para o maior número de pessoas possivel.

Tendo em vista que o trabalho universitário deve conduzir a uma ampla compreensão dos parâmetros histórico-culturais em que qualquer especificidade profissional se realiza e, ao mesmo tempo, ao conhecimento de problemas referentes aos diferentes espaços específicos, é preciso que a Universidade desenvolva um eficaz trabalho de extensão cultural que possa complementar a formação profissional dos seus estudantes, oportunizando, assim, o contato com questões específicas de temas culturais e/ou científicos que não os da carreira escolhida.

Finalmente, o autor indica os valores que deveriam nortear os esforços individuais e coletivos em prol de uma Universidade que pretenda alcançar sua missão precípua: a liberdade, a igualdade e o bem-estar, cuja conjugação e vivência plena tornam possivel uma vida mais digna.

Concejo (1990), tratando do tema Cultura e Universidade, apresenta pontos de convergência com Suchodolski (1979) ao ressaltar que o futuro da sociedade depende da cultura, sendo a tarefa cultural um dos eixos fundamentais na construção de uma nova sociedade.

Também aponta (p. 65), como o referido autor, para a função crítica da Universidade, ao afirmar que esta "deve submeter a cultura, os fenômenos e os valores de seu tempo continuamente a exame. Missão permanente da Universidade é criar cultura e elevar o nível cultural da nação".

Alerta, neste particular, para o fato de que, no fim do nosso século, estão se produzindo significativas mudanças na própria concepção de cultura. Também nesse aspecto a Universidade detém uma enorme responsabilidade, não podendo nem devendo, portanto, colocar-se à margem das tranformações sociais e apontando algumas dicotomias a serem superadas na consecução dessa tarefa.

Entre elas, talvez a mais aguda seja a oposição entre desenvolvimento tecnológico e desenvolvimento humano. A Universidade, na concepção de Concejo (p. 66) deve romper esse distanciamento, sob pena de, ao confundir educar com ensinar $e$ formar com informar, transformar-se em uma fábrica de títulos, deixando de lado o caráter de universalidade que, em suas origens, a caracterizou pela "abertura à totalidade do saber humano e aos problemas que se centram no humanismo integral".

Ao mesmo tempo, não esquece que a Universidade se encontra inserta em um ambiente social impregnado de fortes tensões, e nem sempre é fácil, para ela, como instituição, adequar seu discurso humanístico à forte linguagem das exigências da moderna sociedade de mercado.

Nesse particular, mais uma vez é colocada a missão da Universidade no que concerne à produção da cultura. A autora alerta para o êxodo das funções tradicionalmente acadêmicas para fora de seu âmbito, ao constatar, como outros autores 0 fazem, que a pesquisa de ponta já não mais se encontra nos campi e sim em cen- 
tros especializados, havendo uma quase incomunicabilidade entre a cultura universitária e a cultura avançada dominante.

Para superar esse impasse - propõe a autora (p. 70) - a Universidade "deve ser um centro dedicado à investigação do sentido, à livre reflexão e à educação, indispensáveis para a saúde cultural da nação", destacando, assim, a premência de uma mudança, por parte dos intelectuais e dos universitários, no enfoque de sua tarefa cultural, colocando seu ímpeto e sua capacidade criadora a serviço da sociedade, com a qual tem um compromisso inalienável.

A partir dessas reflexões, Concejo $(1990$, p. 72$)$ explicita qual seja a tarefa da Universidade cristã: "formar as pessoas na liberdade do espírito, levando-as a sentir-se co-responsáveis pelo bem comum, comprometidas na promoção da justiça, na defesa dos mais pobres e no desenvolvimento de todos os povos, de todas as comunidades humanas e de todas as culturas".

Galino (1990) reitera, em seu trabalho, as quatro dimensões que tradicionalmente têm centrado os debates e reflexões sobre a missão da Universidade, e o faz a partir de um enfoque bastante lúcido e atual.

A primeira refere-se à formação de profissionais, sendo este, na percepção da autora, o aspecto mais enfatizador nos dias atuais. Entretanto, como outros autores, entre os quais Escotet (1990), alerta para o descompasso entre o número e as especialidades dos egressos da Academia e as reais necessidades da comunidade, bem como para a conseqüente dificuldade para assimilá-los adequada e produtivamente ao mercado de trabalho.

No que tange à atividade de pesquisa, mais uma vez coincide com a posição de outros estudiosos do tema ao assinalar que não é nem exclusiva nem primordialmente na Academia onde se geram as mais relevantes investigações, postulando uma atitude de autenticidade e realismo no meio universitário para tentar dar conta dessa defasagem.

Dessa forma, manifesta a desatenção e a ineficiência da Universidade quanto à incumbência de proporcionar aos acadêmicos, seja da área científica, seja da humanística, uma adequada e eficaz cultura geral, assinalando a comunicação intercultural, a colaboração interdisciplinar e a vivência plena da comunidade universitária como práticas indispensáveis à otimização do exercício acadêmico.

Por fim, denuncia (p. 56) a crônica desconexão que, com honrosas exceções, existe entre a Universidade e seu entorno, contrariando, assim, sua função específica, já que caberia a ela interagir com a vida pública, e refere Ortega y Gasset quando este afirma: "eu não vos digo isto só porque a excitação animadora do ar histórico convenha à Universidade, senão também vice-versa, porque a vida pública necessita urgentemente da intervenção nela da Universidade".

A autora avança na abordagem do tema ao pontificar (p. 57): "A missão da Universidade está indissoluvelmente ligada à busca de formulação e ensino da verdade. Investigar e formar na verdade". Destaca, então, que uma instituição que tem como meta investigar, aprender e ensinar conhecimentos deve estabelecer uma relação direta com a verdade desses conhecimentos mediante uma intervenção ativa no domínio e transformação da realidade.

É a partir desse ponto de vista que a autora destaca a imprescindivel urgência de assumir novas obrigações sociais, como tarefa das instituições universitárias de 
nossos dias. Corresponde a elas estabelecer uma relação válida entre seus programas e as demandas da sociedade, tendo em vista o desenvolvimento econômico.

Não deve, entretanto, nas palavras de Galino (p. 60-61), descuidar "descobrimento e promoção dos grandes valores éticos da liberdade, co-responsabilidade, de respeito positivo à dignidade do homem e de solidariedade operativa para conseguir a sociedade pluralista e democrática à qual aspiramos", já que "sem eles, os modelos de desenvolvimento economicista adotados até agora no Ocidente seguirão postergando em grande escala o primeiro dos direitos do homem, que é o direito à vida, e ameaçando seriamente a sobrevivência coletiva".

Para lograr alcançar esses objetivos, contudo, é necessária uma radical renovação espiritual, ou seja, um redimensionamento moral e ético das aspirações individuais e sociais. É precisamente aí que a Universidade desempenha um papel decisivo, pois, por sua natureza está - ou deverá estar - em condições de propiciar uma sólida formação humana.

Tendo em vista essa enorme responsabilidade, cabe à Universidade repensar a questão de sua autonomia para poder colocar-se patentemente a serviço da sociedade. Essa autonomia deve conceber-se a partir do princípio da solidariedade social, sendo que, conforme a autora (p. 62) "a potência criadora de sentido que tem a investigação em todos os níveis e a conseguinte capacidade de promover um cultivo de valores que dela pode derivar-se, constituem, essencialmente, a missão da Universidade" [o grifo é nosso].

Ao refletir sobre a relação Universidade-sociedade, Candau (1990) explicita que, como instituição cientifica e educativa, a Universidade possui uma função social que lhe é inerente e não acrescentada a ela de fora para dentro. A maneira como esta relação se estabelece é, contudo, determinada pelos princípios ético-filosóficos que norteiam a sua ação concreta.

A autora aprofunda esse raciocínio empregando a metáfora do claustro e da palestra para caracterizar duas perspectivas da vida universitária que originam diferentes concepções a respeito da missão social que a Universidade deve cumprir.

$\mathrm{Na}$ primeira perspectiva, o núcleo que define a identidade universitária é a Ciência, com ênfase em seu caráter universal e sua autonomia frente à visão e aos condicionamentos do entorno em que se situa, sendo sua preocupação básica a excelência acadêmica, o rigor e a seriedade científica. Assim sendo, a Ciência, com a neutralidade que supostamente a caracteriza, tende a ser o valor absoluto.

Neste tipo de enfoque, se prioriza o trabalho individual e o de grupos homogêneos, preconizando-se, assim, a tranqüilidade e o diálogo como elementos facilitadores do estudo e da pesquisa. Para avaliar a excelência acadêmica, estabelecemse critérios julgados objetivos, balisados principalmente pelas pesquisas e pelas publicações de seus docentes.

Como decorrência lógica, as principais incumbências da Universidade seriam a busca da verdade, a construção do saber científico, a formação de profissionais competentes, a compreensão e explicação da realidade e a colaboração com a sociedade, sem, entretanto, expressar formalmente o tipo de sociedade para a qual volta o seu interesse ou se propõe a ajudar a construir. 
Na dimensão da Universidade palestra, contrariamente, a ênfase é colocada na Ciência, mas buscando constantemente um papel social para a criação científica, mediante a formação de profissionais comprometidos com a transformação social.

A produção do saber é, então, direcionada para o contexto sócio-político, econômico e cultural no qual a Universidade está inserida, sem, contudo, relegar a um segundo plano o caráter universal da Ciência e a própria história da Humanidade.

Dessa forma, a atividade profissional e científica deverá estar dimensionada pela ética e pelo humano. A vivência universitária, nessa perspectiva, deve estar em intima relação de comprometimento com os movimentos sociais, valorizandose o diálogo e a confrontação de posicionamentos ideológicos distintos como elementos salutares para a elaboração de um conhecimento científico pluralista e adequado à prática social.

Fica, dessa maneira, claramente estabelecida a điferenciação quanto à função social que cada uma dessas formas de Universidade estabelece para si.

A Universidade claustro afirma o valor social da Ciência em si mesma, destacando a ética individual no fazer cientifico e profissional. O conhecimento cientifico, sua transmissão, a excelência acadêmica e a competência profissional são vistas como valores sociais em si mesmos, sendo que a evolução da Ciência e da Tecnologia e a formação de profissionais altamente qualificados constituirão a razão de ser da Academia e sua contribuição social.

A Universidade palestra, por sua vez, manifesta sua missão social em nivel diferente, colocando a Academia como espaço privilegiado de uma visão mais crítica da sociedade, participante ativa nos movimentos sociais e altamente comprometida com a mudança do status quo.

A autora (p. 48), lucidamente, esclarece que essas duas facetas da Universidade "representam mais que visões harmônicas explicitamente assumidas por uma instituição concreta [...] movimentos presentes, com maior força, na dinâmica interna da maior das universidades", existindo, sem dúvida, instituições que se aproximam mais a um ou outro desses modelos e, nessa postura explícita ou implicitamente assumida por alguns grupos que a constituem e que desempenham, em determinados momentos, papel hegemônico, pode vir a provocar relações tensas, conflitos e lutas pelo poder.

Acrescenta que é na praxis universitária, manifesta nas atividades que promove, nas decisões que toma, nas linhas de pesquisa que desenvolve, nas publicações que realiza e nos currículos que elabora onde podemos identificar sua tendência por uma ou outra das modalidades propostas.

Candau (p. 53) critica a tendência de ambas as modalidades por sua visão reducionista da função social da Universidade, ao contraporem excelência acadêmica e relevância social, considerando que a questão fulcral reside em trabalhar a articulação entre elas, propondo, para tanto, a tomada de consciência da dimensão ética da Ciência e da Tecnologia em todos os níveis como elemento articulador nesse processo para a construção de uma sociedade mais justa, concluindo que "o desafio da Universidade de hoje é construir em cada contexto sócio-cultural, em cada instituição universitária concreta, em nossa atividade como professores e investigadores, esta 'razão solidária'. Assumir esta perspectiva supōe liberar nossa capacidade criativa e crítica. Exige unir esforços com aqueles que, na vida universitária e 
desde outras mediações científicas, culturais e sociais, acreditam na necessidade de repensar e transformar estruturalmente o mundo em que vivemos".

Hernández (1989) considera que a Universidade, enquanto instituição social, possui incumbências claramente definidas, pois, para ele (p. 303), "a Universidade teoricamente é um grande sistema vivo onde existem funções de input, de produção e de output".

Na função de recepção (de input), destaca quatro maneiras de atuar que podem vir a constituir-se em um elenco de critérios cuja apreciação pode levar a avaliar o patamar de funcionamento de uma Universidade em sua capacidade receptiva: o armazenamento do conhecimento tradicional, produzido por ela mesma através dos tempos; o armazenamento do conhecimento atual, advindo de fontes científicas de informação; a recepção da informação oriunda da própria sociedade e das suas demandas; a retroalimentação de seu próprio funcionamento.

As diferentes formas de levar a efeito e priorizar essas funções de input vão estabelecer, segundo o autor, a linha divisória entre uma Universidade de cunho eminentemente tradicional - preocupada unicamente na acumulação do conhecimento já estabelecido - e uma Universidade de caráter funcional. Esta última caracterizase pela busca de informações de vanguarda mediante o estabelecimento de intercâmbios com outros centros científicos e/ou universitários, sem, contudo, postergar o acúmulo do saber já produzido. Do mesmo modo, uma Universidade moderna há de colocar-se num posicionamento de forte interação com o seu entorno, direcionando os seus esforços no sentido de atender às necessidades e demandas da sociedade, orientando seu fazer em função dessas instâncias. Finalmente, a Universidade pode chegar a um mais alto nivel de aperfeiçoamento institucional à medida que desencadeie processos que conduzam ao conhecimento e à avaliação de seu funcionamento, capazes de servir como instrumentos para a sua retroalimentação e para corrigir e otimizar o seu desempenho.

As funções de produção localizam-se nas atividades de investigação, nos trabalhos de elaboração informativa e na produção tecnológica. Essa dimensão produtiva, segundo o autor, vem a assinalar a identidade peculiar da Universidade frente às demais instituições educativas, pois caso não seja levada a cabo, destaca Hernández (1989, p. 304) "a Universidade se transformará em um mero centro superior de ensino".

Cabe destacar, aqui, que a produção de conhecimento demanda das instituições de ensino superior não somente a estruturação de um corpo de pesquisadores altamente qualificados e a obtenção de recursos financeiros para incrementar as atividades de investigação. É preciso que se instaurem pressupostos epistemológicos que direcionem essa atividade a um diálogo constante com o espaço sociopolitico e cultural e com as circunstâncias históricas com que a Universidade se interpenetra. A esse respeito, assim se manifesta Marques (1993, p. 22): "Em seu compromisso com a investigação, os grupos de pesquisa problematizam a realidade, buscando as verdades que mudam as concepções do homem sobre o universo e sobre si mesmo".

Quanto às funções de output da Universidade, Hernández (1989, p. 304) aponta três vias: o ensino, a difusão científica e a oferta técnica. $O$ ensino, na opinião do autor, tem uma dupla finalidade: proporcionar ao alunado uma formação cultural 
superior "como cultivo intelectual e enriquecimento social" e formar profissionais qualificados voltados para servir a sociedade. Consideramos que o ensino é, sem dúvida, a mais tradicional das funções de output da Universidade, principalmente por sua responsabilidade de prover a sociedade de indivíduos capazes de contribuir na transformação da realidade social vigente. Contudo, só alcança seu propósito precípuo se for encarado através de um prisma mais abrangente, como parte de um amplo processo de educação que, como fenômeno de transformação, ajuda a reformular o ser humano e a sociedade.

A segunda função de saída - a difusão científica - visa à transmissão dos resultados da produção da Universidade à comunidade científica, num intercâmbio profícuo e enriquecedor com outras instâncias do conhecimento, e vai decorrer diretamente do volume, relevância e qualidade de sua produção.

A oferta técnica constitui-se naquilo que a Universidade, como empresa, tem condições de oferecer à sociedade mediante trabalhos especializados os mais diversos, como, por exemplo, assessorias, elaboração de projetos, consultorias ou tecnologia especializada. Esse é, entretanto, um aspecto que caracteriza as universidades mais modernas e avançadas tecnologicamente que funcionam, em sua maioria, em países do Primeiro Mundo e, sem a menor sombra de dúvida, uma meta a ser tenazmente perseguida por qualquer Universidade.

As universidades, de acordo com as prioridades que estabelecem para si e as metas que se propõem a alcançar, direcionam sua atividade mais enfaticamente para uma ou outra das funções especificadas por esse autor, se se preocupar em privilegiar igualitariamente as três. Entretanto, verifica-se que, em qualquer dos casos, as questões ligadas ao aspecto psicopedagógico ou didático são, não raro, relegadas a um segundo plano e consideradas como acessórias no fazer acadêmiCo.

A importância dada a esses aspectos está diretamente ligada ao conceito de Universidade que seus dirigentes e/ou colegiados possuam.

Hernández (1989) expōe que o aspecto psicopedagógico se valorizará mais em universidades onde se der tanta ou mais importância à atividade docente do que à pesquisa. No momento em que os docentes se sentirem mais incentivados à produção científica, à elaboração de publicações e à participação em eventos científicos, a tarefa docente dentro da sala de aula será paulatinamente deixada em segundo plano, gerando, assim, um pernicioso distanciamento entre a função de produção e a de output.

O mesmo ocorrerá quando a Universidade se acomodar à inércia do fazer acadêmico tradicional, sem buscar adequar o ensino e a formação de profissionais aos perfís que demandam as necessidades nas novas conjunturas sociais.

Por outro lado, o desejo de formar profissionais comprometidos com as transformações sociais redundará numa valorização do docente como elemento que alavanca esse processo e num investimento mais significativo no aperfeiçoamento do quadro docente da Universidade

Assim, qualquer atitude no sentido de melhorar a formação psicopedagógica do docente universitário vai reverter de forma altamente positiva dentro das funções de output no que se refere ao ensino, pois, proporcionará, segundo Hernández (1989, p. 306) "uma maior motivação e satisfação na aprendizagem por parte dos 
alunos", fazendo que estes interiorizem, vitalizem e apliquem de maneira mais eficaz as informações recebidas.

A Universidade que privilegiar o aspecto psicopedagógico, segundo o autor ( $\mathrm{p}$. 306), se caracterizará por um ensino que "contempla os aspectos não só informativos senão também os formativos e que se ajusta mais adequadamente aos perfis profissionais demandados pela sociedade".

Destaca ainda o autor que o aperfeiçoamento docente no que tange ao aspecto psicopedagógico e metodológico vai definir uma estruturação e operacionalização mais eficientes dos conteúdos cientificos, fomentando, ao mesmo tempo, uma reflexão mais acurada sobre a elaboração dos conteúdos e dos currículos a serem desenvolvidos.

Ainda, a valorização do aperfeiçoamento psicopedagógico do corpo docente da Universidade implica, como destaca Hernández (1989, p. 307), "maior nível de organização, de motivação, de comunicação humana e de reflexão sobre os objetivos educativos", podendo vir a constituir-se em um caminho para potenciar a renovação educativa da Universidade e, conseqüentemente, uma forma para ela poder cumprir efetivamente com sua responsabilidade social, sendo, conforme Hernádez (1989, p. 307) explicita "favorável para a motivação e satisfação dos alunos, para o desenvolvimento da ciência, e para uma melhor preparação profissional no serviço à sociedade".

O posicionamento dos autores aqui analisados nos encaminha a uma profunda reflexão quanto ao presente e ao futuro da Universidade, instituição enraizada em um contexto social cada vez mais conturbado e contraditório, onde os valores humanos passam por uma crise inusitada.

Num mundo onde o egoísmo é a tônica principal e a solidariedade vem sendo substituída pela competitividade, onde a Ciência tem conduzido o homem pelo caminho da racionalidade, da desumanização e da desestruturação das relações interpessoais, devemos pensar a Universidade como a instância responsável por um projeto que venha a reverter essa realidade, que crie espaços para um amplo debate no sentido de inserir-se na dinâmica das mudanças sociais, científicas e tecnológicas intrínsecas à essência e ao futuro da educação, com vistas à construção de uma sociedade mais democrática e mais participativa.

Tudo o que foi dito até o presente momento encontra-se sintetizado no esquema geral que a seguir colocamos. 


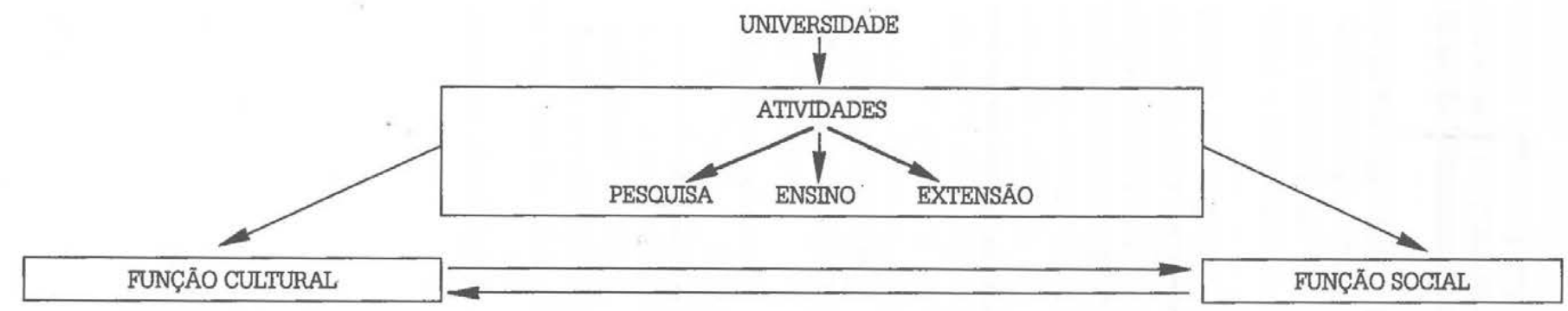

- Preservação do saber

- tradição e avanços

- socialização

- Transmissão do saber

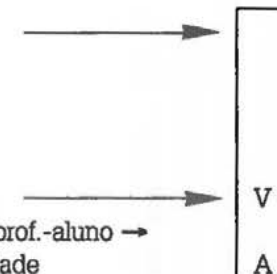

questonamento $\rightarrow$ interacão prof crítica e autocrítica $\rightarrow$ qualidade

- debates

- Aumento e

enriquecimento do saber

- pesquisa $\rightarrow$ avanço da ciência
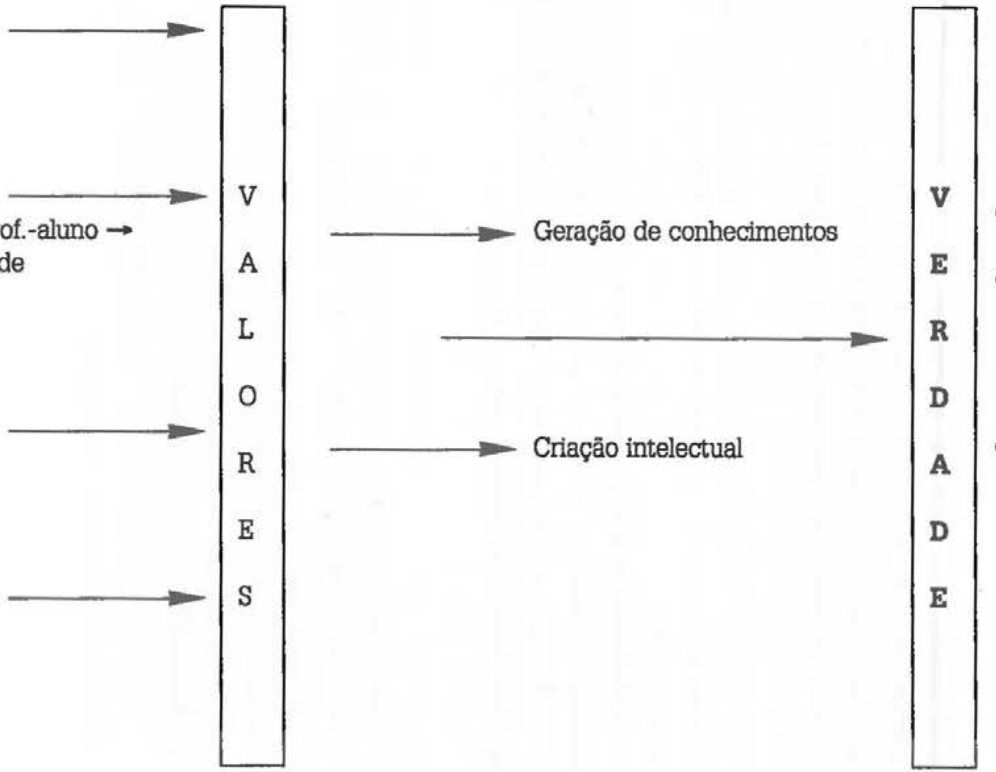

$\Rightarrow \quad \Rightarrow \quad$\begin{tabular}{|l|}
\hline \\
S \\
O \\
C \\
$\mathrm{I}$ \\
$\mathrm{E}$ \\
$\mathrm{D}$ \\
$\mathrm{A}$ \\
$\mathrm{D}$ \\
$\mathrm{E}$ \\
$\mathrm{D}$ \\
$\mathrm{O}$ \\
$\mathrm{F}$ \\
$\mathrm{U}$ \\
$\mathrm{T}$ \\
$\mathrm{T}$ \\
$\mathrm{U}$ \\
$\mathrm{R}$ \\
$\mathrm{O}$ \\
\hline
\end{tabular}

- Assimilação e "digestão" intelectual do saber

- reflexão

- aplicação a problemas práticos

$\rightarrow$ interdiscuplinariedade

$\rightarrow$ crítica e autocrítica

- Formação de profissionais

- Formação global

do homem p/a mudança

permanente

- Acompanhar e provocar mudanças na sociedade 


\section{Referências bibliográficas}

AZEVEDO, Marcelo de C. "Modernidade e função social da Universidade na América Latina". Nuevamérica, Buenos Aires, n. 52, p. 11-13, dic. 1991.

BERCHEN, Theodor. "A missão da Universídade na formação e no desenvolvimento culturais: a diversidade no seio da universalidaden In: Pontificia Universidade Católica do Rio Grande do Sul. Temas Universitários I. Porto Alegre: PUCRS, 1992, p. 34-48.

CALERA, Nicolás López. "La función social de la Universidad". In: FRANCO, Eloisa López, OCHOA, Carmen Fernández, FLECHA, Consuelo, TORRES, Isabel (ed.). La función social de la Universidad. Madrid: Narcea, 1990, p. 17-25.

CANDAU, Vera Maria. "La Universidad hoy: entre el 'claustro' y la 'palestra'". In: FRANCO, Eloísa López, OCHOA, Carmen Fernández, FLECHA, Consuelo, TORRES, Isabel (ed.). La función social de la Universidad. Madrid: Narcea, 1990, p 47-54.

CONCEJO, Pilar. "Cultura y Universidad". In: FRANCO, Eloísa López, OCHOA, Carmen Fernández, FLECHA, Consuelo, TORRES, Isabel (ed.). La función social de la Universidad. Madrid: Narcea, 1990, p. 65-72.

ESCOTET, Miguel Ángel. "Visión de la Universidad del siglo XXI: dialéctica de la misión universitária en una era de cambios". Revista Española de Pedagogia, Madrid, ano XLVII, n. 186, p. 211-228, mayoagosto, 1990.

- . Aprender para el futuro. Madrid: Alianza Editorial, 1992.

GALINO, Angeles. "Misión de la Universidad. In: FRANCO, Heloísa Lópes, OCHOA, Carmen Fernández, FLECHA, Consuelo, TORRES, Isabel (ed.). La función social de la Universidad. Madrid: Narcea, 1990, p. 54-63.

HERNÁNDEZ, Pedro. Diseñar y Enseñar. Teoria y Técnicas de la Programación y del Proyecto Docente. Madrid: Narcea, 1989.

MAROUES, Juracy C. "Que faz a Universidade: suas propostas e seus papéis sociais". Educação, Porto Alegre, ano XVI, n. 25, p. 19-34, 1993.

MOSOUERA, Juan José Mouriño. "Universidade e produção de conhecimento". In: Logos, Canoas, ano 2, n. 27 p. 6-8, $2^{2}$ semestre 1990.

- "O aluno e a aprendizagem de valores". In: ENRICONE, Delcia (ed.). Valores no processo educativo. 2 ed., Porto Alegre: EDIPUCRS, 1992, p. 46-54.

SUCHODOLSKI, Bodgan. Tratado de Pedagogía. Barcelona: Península, 1979.

ZILLES, Urbano. "Valores no mundo de hoje". In: ENRICONE, Delcia (ed.). Valores no processo educativo. 2 ed., Porto Alegre: EDIPUCRS, 1992, p. 32-45. 